\title{
Correlation of left ventricular mass determined by echocardiography with vectorcardiographic and electrocardiographic voltage measurements
}

\author{
D. H. Bennett and D. W. Evans \\ From the Regional Cardiac Unit, Papworth Hospital, Cambridge
}

Left ventricular mass, derived from echocardiographic measurement of left ventricular wall volume, was compared with simple vectorcardiographic and electrocardiographic voltage measurements in 36 patients with left ventricular enlargement and 7 normal subjects. Left ventricular wall volume was obtained by subtracting the volume of the ventricular cavity, calculated as the cube of the ultrasound internal dimension, from the volume occupied by ventricular wall and cavity, calculated as the cube of the internal dimension plus twice the wall thickness. This method differs from those used hitherto and appears preferable on theoretical grounds.

The mass measurements correlated closely with the vectorcardiographic horizontal, and summed horizontal and sagittal, maximum $Q R S$ vectors $(r=0.90)$ and less closely with Sokalow's electrocardiographic criterion $(r=0.73)$.

Both the voltage and echocardiographic measurements are useful techniques for assessing left ventricular mass, particularly for serial observations. Where echocardiography is not practicable or available, simple vectorcardiographic measurements offer an alternative means of estimating left ventricular mass.

Measurement of left ventricular mass can be useful in the diagnosis and assessment of disorders which may involve this chamber of the heart. The best in vivo measurements are provided by angiocardiographic techniques, but their use is restricted to a small proportion of patients, and opportunities for serial measurements rarely arise.

Echocardiographic measurement of left ventricular mass has been shown to correlate closely with its measurement by angiocardiography (Troy, Pombo, and Rackley, 1972; Murray, Johnston, and Reid, 1972) and has the advantage of being noninvasive and easily repeatable. However, the technique can be difficult, or even impossible, to perform on some patients and requires some small measure of skill.

Of the noninvasive techniques for the detection and assessment of left ventricular enlargement, the most generally available is conventional scalar electrocardiography. Spatial vectorcardiography, using a corrected orthogonal lead system, is claimed by some to be a superior method (Bristow, Porter, and Griswold, 196r; Mazzoleni, Wolff, and Wolff, 1962; Abbott-Smith and Chou, 1970); however,

Received 9 April 1974. most studies have involved complex computations of the vectorcardiographic data.

In this study the relations between simple vectorcardiographic, scalar electrocardiographic (Sokalow and Lyon, 1949), and ultrasound measurements of left ventricular size, were examined in normal subjects and those with left ventricular overload, where uniformity of left ventricular wall thickness could reasonably be assumed.

\section{Subjects and methods}

Comparative data were obtained from 36 male patients with disorders likely to cause left ventricular enlargement and from 7 normal male subjects. The ages and diagnoses of these patients are given in Table I. Data obtained from a further 9 patients were not included in the analysis because satisfactory echocardiograms could not be obtained. Patients with hypertrophic cardiomyopathy or myocardial infarction, in whom pronounced variations in left ventricular wall thickness may occur, were excluded from the study because the echocardiographic method, like the angiocardiographic method, of estimation of left ventricular mass is based on the assumption of uniform wall thickness. Patients with conduction defects were also excluded.

Echocardiograms were recorded on polaroid film 


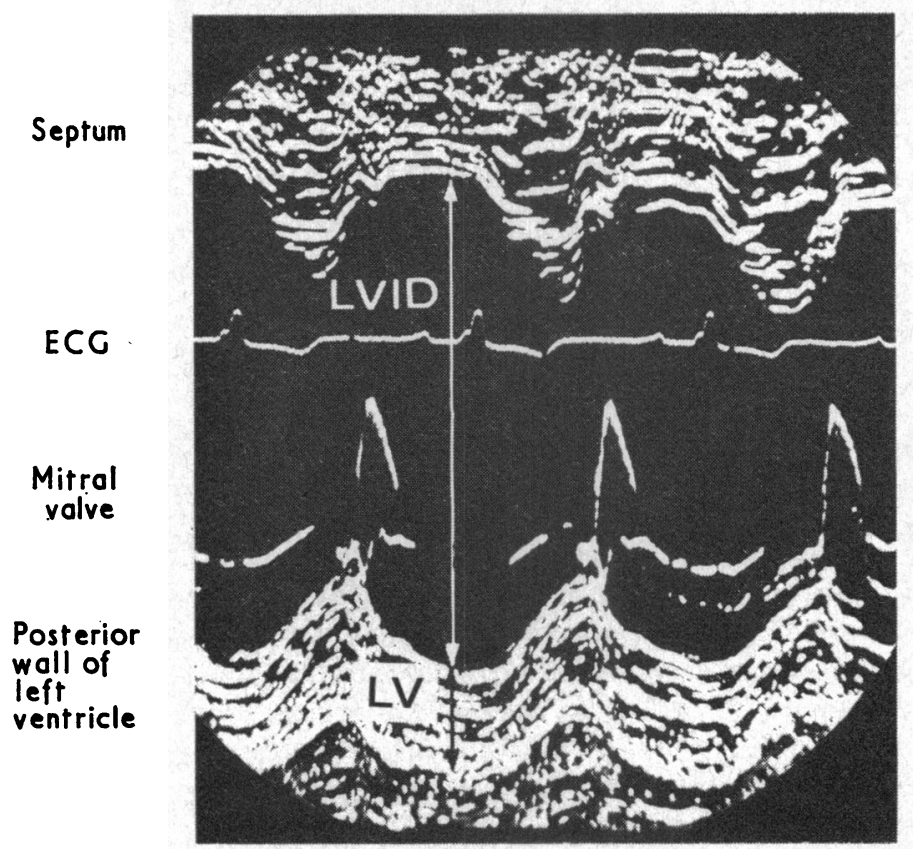

FIG. I Echocardiogram showing diastolic left ventricular wall thickness (LV) and internal dimension (LVID) in a patient with severe aortic incompetence.

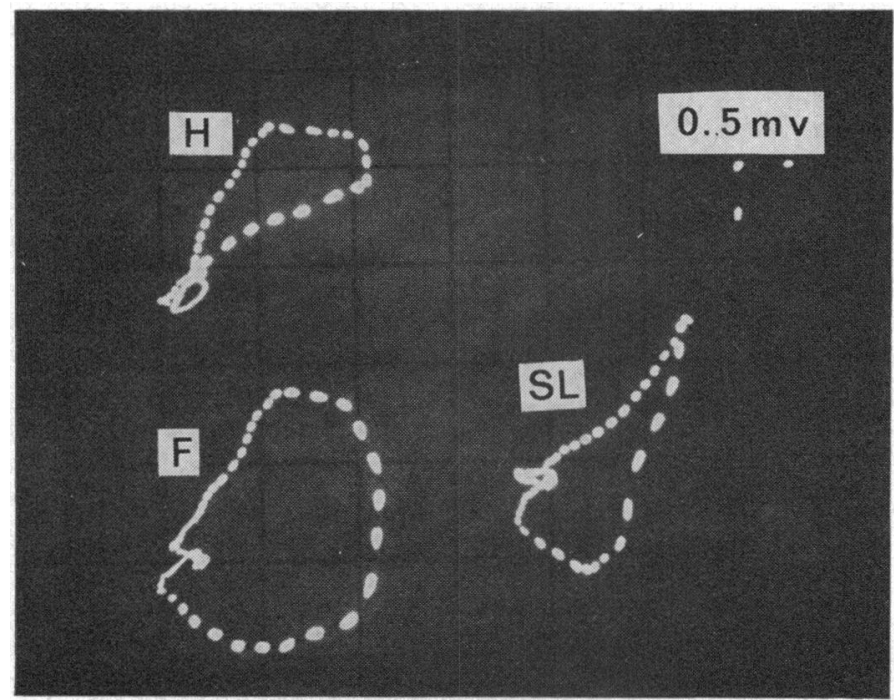

FIG. 2 Vectorcardiogram recorded from a patient with severe aortic regurgitation. Horizontal $(H)$, frontal $(F)$ and left sagittal $\left(S_{L}\right)$ planes. Dashes are at intervals of $2.5 \mathrm{msec}$, the blunt ends indicating direction of loop inscription. 
TABLE I Subject's details and ultrasound data

\begin{tabular}{|c|c|c|c|c|c|}
\hline \multirow[t]{2}{*}{ Subject } & \multirow{2}{*}{$\begin{array}{l}\text { Age } \\
(y r)\end{array}$} & \multirow[t]{2}{*}{ Diagnosis } & \multicolumn{3}{|c|}{ Left ventricular measurements } \\
\hline & & & $\begin{array}{l}\text { Wall } \\
\text { thickness (mm) }\end{array}$ & $\begin{array}{l}\text { Internal } \\
\text { dimension }(\mathrm{mm})\end{array}$ & $\begin{array}{l}\text { Mass* } \\
(g)\end{array}$ \\
\hline $\mathbf{I}$ & $4 I$ & Aortic regurgitation & 13 & 63 & 480 \\
\hline 2 & 33 & ” & 12 & 61 & 410 \\
\hline 3 & 29 & و & I5 & 67 & 640 \\
\hline 4 & 26 & 9 & 13 & 52 & 350 \\
\hline 5 & 29 & " & 12 & 62 & 420 \\
\hline 6 & 22 & " & 15 & 62 & 570 \\
\hline 7 & 44 & " & 18 & 60 & 700 \\
\hline 8 & 46 & " & 14 & 60 & 490 \\
\hline 9 & 34 & 川 & 13 & 40 & 240 \\
\hline Io & 69 & Aortic stenosis & 16 & 45 & 380 \\
\hline II & 20 & , & 12 & 53 & 320 \\
\hline 12 & 42 & " & 15 & 53 & 440 \\
\hline 13 & $6 I$ & " & 22 & 36 & 490 \\
\hline I4 & 33 & 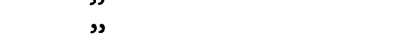 & 12 & 49 & 290 \\
\hline 15 & 57 & 川 . . . . . . & 14 & 62 & 520 \\
\hline 16 & 33 & Aortic stenosis and regurgitation & 13 & 80 & 710 \\
\hline 17 & 56 & & 16 & 49 & 430 \\
\hline 18 & 47 & Mitral and aortic regurgitation & 19 & 58 & 720 \\
\hline 19 & 66 & & 12 & 80 & 640 \\
\hline 20 & $6 I$ & Mitral regurgitation & I0 & 70 & 400 \\
\hline 21 & $4 I$ & g) & 17 & 50 & 490 \\
\hline 22 & 48 & " & 8 & 79 & 380 \\
\hline 23 & 26 & Aortic prosthesis & 13 & 72 & 600 \\
\hline 24 & 50 & 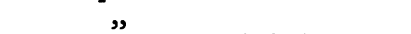 & 16 & 57 & 550 \\
\hline 25 & 26 & Aortic paraprosthetic leak & 15 & 46 & 360 \\
\hline 26 & 44 & , & 13 & 60 & 440 \\
\hline 27 & 61 & ” & 16 & 64 & 650 \\
\hline 28 & 44 & Leaking aortic homograft & 17 & 73 & 880 \\
\hline 29 & 32 & " & 15 & 67 & 640 \\
\hline 30 & 59 & Mitral and aortic prostheses & 13 & 59 & 430 \\
\hline $3 \mathbf{I}$ & 43 & Leaking aortic and mitral valve & & & \\
\hline & & homografts & 17 & 67 & 770 \\
\hline 32 & 37 & Hypertension & 12 & 65 & 450 \\
\hline 33 & 27 & , & I0 & 55 & 270 \\
\hline 34 & 51 & 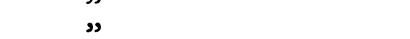 & 15 & 48 & 380 \\
\hline 35 & 62 & " & 15 & 60 & 540 \\
\hline 36 & 37 & & 12 & 54 & 330 \\
\hline 37 & 26 & Normal & Io & 43 & 180 \\
\hline 38 & 27 & g & I0 & 46 & 200 \\
\hline 39 & 29 & " & 9 & 54 & 230 \\
\hline 40 & 28 & , & 10 & 37 & 140 \\
\hline 41 & 28 & " & 10 & 50 & 230 \\
\hline $\begin{array}{l}41 \\
42\end{array}$ & 30 & " & 10 & 49 & 220 \\
\hline 43 & 26 & " & Io & 40 & 160 \\
\hline
\end{tabular}

* Approximated to nearest $10 \mathrm{~g}$.

using an Eskoline 20 ultrasonoscope and a $2 \cdot 25 \mathrm{MHz}$ general purpose transducer. The transducer was placed parasternally on the left fourth or fifth intercostal space and directed posteriorly and slightly medially until the characteristic motion of the anterior mitral cusp was identified. The transducer was then angled slightly inferiorly and laterally until, with adjustment of depth compensation, gain, and reject controls, the posterior wall of the left ventricle and interventricular septum were located. As recommended by Feigenbaum (I972), part of the mitral valve apparatus was included on the record to ensure that the ultrasound beam did not pass too near to the apex and possibly give an inappropriately small measurement of left ventricular internal dimension, and also in an attempt to obtain a 'standardized" left ventricular internal dimension. Left ventricular wall thickness (LV) was measured as the distance between the inner surface of the endocardium and the outer surface of the epicardium. The left ventricular internal dimension (LVID) was measured as the distance between the endocardium of the interventricular septum and that of the posterior wall. Both measurements were made at 
the onset of the $\mathbf{R}$ wave of the simultaneously recorded electrocardiogram (Fig. I).

Left ventricular wall volume was calculated using the following formula:

Left ventricular wall volume $=(2 \mathrm{LV}+\mathrm{LVID})^{3}$ -(LVID) $)^{3}$.

This formula differs from those used by Troy et al. (1972) and Murray et al. (1972). The reasons for its preference are discussed later.

The resultant muscle volume was multiplied by $\mathbf{r} \cdot 05$, the specific gravity of cardiac muscle (Bardeen, 1918) in order to obtain left ventricular mass.

Spatial vectorcardiograms were recorded on polaroid film using a Hewlett-Packard I520A vectorcardiograph and the Frank electrode system (Frank, 1956). The chest electrodes were placed over the fifth intercostal space. The maximum QRS vectors, i.e. the distance between the point of origin and most remote point in the QRS loop, were measured in the horizontal $(H)$, frontal $(F)$, and left sagittal $\left(S_{\mathrm{L}}\right)$, planes. (Fig. 2). The maximum QRS axes in the horizontal and sagittal $\left(H+S_{L}\right)$, and horizontal and frontal $(\mathbf{H}+\mathbf{F})$, planes were summed.

Standard 12-lead electrocardiograms were recorded with particular attention to accurate placement of the chest electrodes. The amplitudes of the $S$ wave in lead VI and the $R$ waves in leads V5 and V6 were measured. The sum of the voltage of the $S$ wave in lead VI and the

TABLE 2 Vectorcardiographic and electrocardiographic data

\begin{tabular}{|c|c|c|c|c|c|c|c|c|}
\hline \multirow[t]{2}{*}{ Subject } & \multicolumn{5}{|c|}{ Vectorcardiographic maximum $Q R S$ vectors $(m V)$} & \multicolumn{3}{|c|}{ Electrocardiographic voltage measurements $(m V)$} \\
\hline & $H$ & $\boldsymbol{F}$ & $S_{\mathrm{L}}$ & $H+S_{\mathrm{L}}$ & $H+F$ & $S$ in $V I$ & $R$ in $V 5$ or $V 6$ & $S V_{I}+R V_{5}$ or $V 6$ \\
\hline $\mathbf{I}$ & $2 \cdot 9$ & $\mathbf{2} \cdot 3$ & $2 \cdot 1$ & $5 \cdot 0$ & $5 \cdot 2$ & $3 \cdot 6$ & $4 \cdot 0$ & $7 \cdot 6$ \\
\hline 2 & $1 \cdot 9$ & $2 \cdot 0$ & 0.9 & $\mathbf{2} \cdot 8$ & $3 \cdot 9$ & $I \cdot 0$ & $2 \cdot 4$ & $3 \cdot 4$ \\
\hline 3 & $2 \cdot 8$ & $3 \cdot 7$ & $4 \cdot 3$ & $7 \cdot 1$ & $6 \cdot 5$ & $3 \cdot 0$ & $2 \cdot 6$ & $5 \cdot 6$ \\
\hline 4 & $2 \cdot 0$ & $2 \cdot I$ & I.5 & 3.5 & $4 \cdot I$ & $1 \cdot 5$ & $2 \cdot 2$ & $3 \cdot 7$ \\
\hline 5 & 2.6 & $2 \cdot 4$ & $\mathbf{I} \cdot 8$ & 4.4 & $5 \cdot 0$ & $3 \cdot 1$ & $3 \cdot 2$ & $6 \cdot 3$ \\
\hline 6 & $3 \cdot 3$ & $3 \cdot 0$ & $3 \cdot 3$ & $6 \cdot 6$ & $6 \cdot 3$ & 4.0 & $2 \cdot 8$ & 6.8 \\
\hline 7 & 3.9 & $2 \cdot 2$ & $3 \cdot 3$ & $7 \cdot 2$ & $6 \cdot 1$ & 3.8 & $3 \cdot 8$ & $7 \cdot 4$ \\
\hline 8 & $2 \cdot 3$ & I.9 & $2 \cdot 3$ & $4 \cdot 6$ & $4 \cdot 2$ & $1 \cdot 9$ & 2.9 & $4 \cdot 8$ \\
\hline 9 & $I \cdot 7$ & $1 \cdot 6$ & $1 \cdot 5$ & $3 \cdot 2$ & $3 \cdot 3$ & $2 \cdot I$ & $\mathbf{I} \cdot \mathbf{2}$ & $3 \cdot 3$ \\
\hline I0 & $2 \cdot 3$ & $2 \cdot 0$ & $1 \cdot 6$ & 3.9 & $4 \cdot 3$ & $2 \cdot 0$ & $2 \cdot 7$ & 47 \\
\hline II & 2.5 & $2 \cdot 2$ & $1 \cdot 9$ & 4.4 & 4.7 & $2 \cdot 7$ & 2.9 & $5^{\cdot 6}$ \\
\hline 12 & $2 \cdot 9$ & $3 \cdot 0$ & $2 \cdot 3$ & $5 \cdot 2$ & $5 \cdot 1$ & $2 \cdot 2$ & $4 \cdot 0$ & $6 \cdot 2$ \\
\hline 13 & 2.5 & 2.5 & 2.7 & $5 \cdot 2$ & 50 & $2 \cdot 4$ & 37 & $6 \cdot 1$ \\
\hline 14 & $1 \cdot 6$ & $2 \cdot I$ & $1 \cdot 5$ & $3 \cdot 1$ & $3 \cdot 7$ & $I \cdot 3$ & $2 \cdot 0$ & $3 \cdot 3$ \\
\hline 15 & $2 \cdot 8$ & $2 \cdot 8$ & $\mathbf{I} \cdot \mathbf{8}$ & $4 \cdot 6$ & $5 \cdot 6$ & 3.4 & 3.6 & $7 \cdot 0$ \\
\hline 16 & $4 \cdot I$ & $4 \cdot I$ & 3.0 & $7 \cdot 1$ & $8 \cdot 2$ & 3.2 & $5 \cdot 8$ & 9.0 \\
\hline 17 & $2 \cdot 6$ & $2 \cdot 1$ & 2.5 & $5 \cdot 1$ & 47 & $2 \cdot 8$ & 3.2 & $6 \cdot 0$ \\
\hline 18 & 3.7 & $2 \cdot 3$ & 3.6 & $7 \cdot 3$ & 6.0 & $3 \cdot 0$ & 3.9 & 6.9 \\
\hline 19 & 4.4 & $4 \cdot 2$ & $2 \cdot 3$ & 6.6 & 8.6 & I.9 & $2 \cdot 9$ & $4 \cdot 8$ \\
\hline 20 & $2 \cdot 1$ & $2 \cdot 4$ & $1 \cdot 8$ & $3 \cdot 8$ & 4.5 & $I \cdot 2$ & $2 \cdot 4$ & 3.6 \\
\hline 21 & 2.7 & $3 \cdot 6$ & 2.5 & $5 \cdot 2$ & $6 \cdot 3$ & 40 & $4 \cdot 3$ & $4 \cdot 7$ \\
\hline 22 & $1 \cdot 8$ & 0.9 & $2 \cdot 0$ & 3.8 & $2 \cdot 7$ & $\mathbf{I} \cdot \mathbf{2}$ & $I \cdot 2$ & 2.4 \\
\hline 23 & $2 \cdot 6$ & $2 \cdot 0$ & $2 \cdot 7$ & $5 \cdot 3$ & $4 \cdot 6$ & $2 \cdot 2$ & $3 \cdot 3$ & 5.5 \\
\hline 24 & 2.5 & $1 \cdot 7$ & $2 \cdot 4$ & 4.9 & $4 \cdot 2$ & 3.5 & $2 \cdot I$ & 5.6 \\
\hline 25 & $2 \cdot 7$ & $2 \cdot 6$ & $\mathbf{I} \cdot \mathbf{8}$ & 4.5 & $5 \cdot 3$ & $I \cdot 7$ & $3 \cdot 1$ & $4 \cdot 8$ \\
\hline 26 & $2 \cdot 2$ & $2 \cdot 2$ & $2 \cdot 2$ & 44 & 4.4 & 2.9 & $2 \cdot 0$ & 4.9 \\
\hline 27 & 3.5 & 2.0 & 2.8 & $6 \cdot 3$ & 5.5 & 2.7 & 2.5 & $5 \cdot 2$ \\
\hline 28 & 3.5 & $2 \cdot 7$ & 2.6 & $6 \cdot 1$ & $6 \cdot 2$ & 2.8 & 4.7 & $7 \cdot 5$ \\
\hline 29 & 3.5 & I.5 & 3.5 & $7 \cdot 0$ & 5.0 & 2.5 & $2 \cdot 7$ & $5 \cdot 2$ \\
\hline 30 & 2.6 & $I \cdot 6$ & $2 \cdot 4$ & 50 & $4 \cdot 2$ & $1 \cdot 5$ & 2.5 & 40 \\
\hline 31 & $4 \cdot 2$ & $2 \cdot 4$ & $4 \cdot 0$ & $8 \cdot 2$ & 6.6 & 2.5 & $2 \cdot 3$ & $4 \cdot 8$ \\
\hline 32 & $1 \cdot 9$ & $\mathbf{I} \cdot \mathbf{3}$ & $2 \cdot 2$ & $4 \cdot I$ & $3 \cdot 2$ & $2 \cdot 0$ & $I \cdot 4$ & 3.4 \\
\hline 33 & $2 \cdot 0$ & $2 \cdot 7$ & $\mathbf{I} \cdot 8$ & 3.8 & 47 & 2.4 & 2.4 & $4 \cdot 8$ \\
\hline 34 & $\begin{array}{l}1 \cdot 9 \\
\end{array}$ & 1.9 & $\mathrm{I} \cdot 4$ & $3 \cdot 3$ & 3.8 & 3.0 & $\mathbf{1} \cdot 3$ & $4 \cdot 3$ \\
\hline 35 & 2.8 & $\mathbf{I} \cdot 9$ & $\mathbf{I} \cdot 8$ & $4 \cdot 6$ & 47 & $2 \cdot 2$ & 2.6 & $4 \cdot 8$ \\
\hline 36 & $2 \cdot 0$ & $\mathbf{r} \cdot 9$ & 2.0 & 4.0 & 3.9 & $I \cdot 3$ & $2 \cdot 6$ & 3.9 \\
\hline 37 & 1.5 & $1 \cdot 9$ & 1.5 & 30 & $3 \cdot 4$ & I.7 & I.8 & 3.5 \\
\hline 38 & $1 \cdot 4$ & $2 \cdot 0$ & I.8 & 3.2 & 3.4 & $\mathbf{I} \cdot \mathbf{O}$ & $2 \cdot 0$ & 30 \\
\hline 39 & $\mathbf{I} \cdot \mathbf{O}$ & $1 \cdot 5$ & $1 \cdot 3$ & $2 \cdot 3$ & 2.5 & $I \cdot 2$ & $1 \cdot 3$ & 2.5 \\
\hline 40 & 0.9 & I.7 & I.4 & $2 \cdot 3$ & $2 \cdot 6$ & 0.5 & $I \cdot 4$ & $1 \cdot 9$ \\
\hline 4I & $\mathbf{I} \cdot \mathbf{2}$ & $\mathbf{I} \cdot 8$ & $\mathbf{I} \cdot 6$ & 2.8 & 30 & $\mathbf{I} \cdot \mathbf{2}$ & $1 \cdot 7$ & $2 \cdot 9$ \\
\hline 42 & $\mathbf{1} \cdot 7$ & 2.5 & $2 \cdot 1$ & 3.8 & $4 \cdot 2$ & $1 \cdot 3$ & $\mathrm{I} \cdot 8$ & $3 \cdot 1$ \\
\hline 43 & $\mathbf{I} \cdot 7$ & $\mathbf{I} \cdot 7$ & $\mathbf{I} \cdot \mathbf{I}$ & $2 \cdot 8$ & 3.4 & $1 \cdot 3$ & $2 \cdot 3$ & 3.6 \\
\hline
\end{tabular}


TABLE 3 Regression data $(y=b x+a)$ and correlation coefficients $(r)$

\begin{tabular}{|c|c|c|c|c|}
\hline$y$ & $x$ & Slope (b) & Intercept (a) & $r$ \\
\hline Ultrasound left ventricular mass & $\left\{\begin{array}{l}\mathrm{H}+\mathrm{S}_{\mathrm{L}} \\
\mathrm{H}+\mathrm{F} \\
\mathbf{H} \\
\mathbf{S}_{\mathrm{V} 1}+\mathbf{R}_{\mathrm{V} 5} \text { or } \mathbf{v 6}\end{array}\right.$ & $\begin{array}{r}108 \cdot 6 \\
102 \cdot 2 \\
186 \cdot 8 \\
80 \cdot 0\end{array}$ & $\begin{array}{r}-65 \cdot 7 \\
-36 \cdot 2 \\
-17 \cdot 9 \\
59 \cdot 6\end{array}$ & $\left.\begin{array}{l}0.903 \\
0.780 \\
0.895 \\
0.730\end{array}\right\} P<0.001$ \\
\hline
\end{tabular}

$R$ wave in $V_{5}$ or V6, whichever was greater, was used as an index of praecordial voltage (Sokalow and Lyon, 1949).

The ultrasound and voltage $\left(H, H+S_{L}, H+F\right.$, $S_{v_{1}}+R_{\left.V_{5} \text { or } v_{6}\right)}$ data were submitted to stepwise linear regression analysis. Significance levels $(P)$ were obtained from tables. The correlation coefficients $(r)$ relating to $\mathrm{H}+\mathrm{S}_{\mathrm{L}}$ and $\mathrm{S}_{\mathrm{V} 1}+\mathrm{R}_{\mathrm{v} 5}$ or v6 were tested for significant difference by $Z$ transformation.

\section{Results}

The ultrasound data are given in Table I. Vectorcardiographic and electrocardiographic data are given in Table 2. There was a good correlation between left ventricular mass determined by echocardiography and the various voltage measurements (Table 3). The correlation between ultrasound left ventricular mass and $\mathrm{H}+\mathrm{S}_{\mathrm{L}}$ and $\mathrm{S}_{\mathrm{V} 1}+$ $R_{\mathrm{V} 5}$ or v6 are illustrated in Fig. 3 and 4 , respectively.

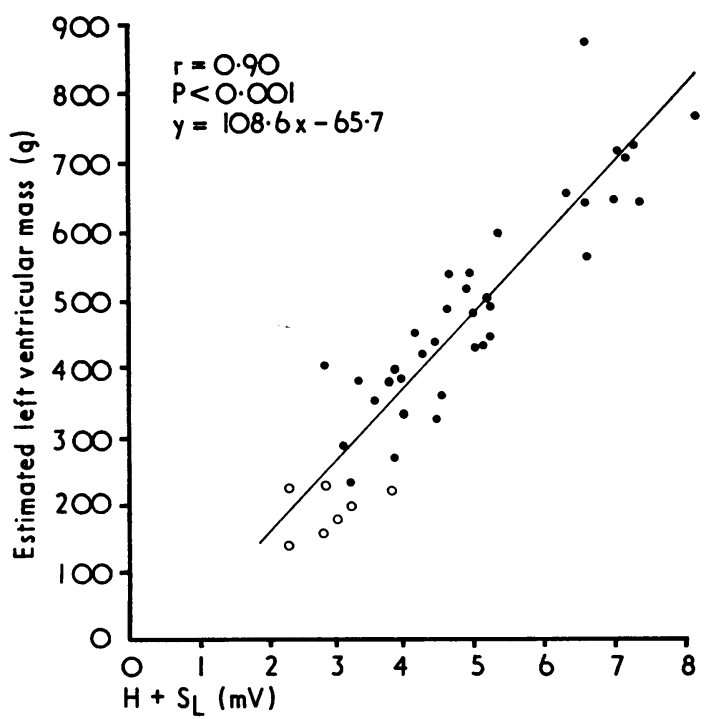

FIG. 3 Relation between left ventricular mass determined echocardiographically and the sum of the maximum vectors in the horizontal and saggital planes of the vectorcardiogram. Open circles = normal subjects; dots = patients.

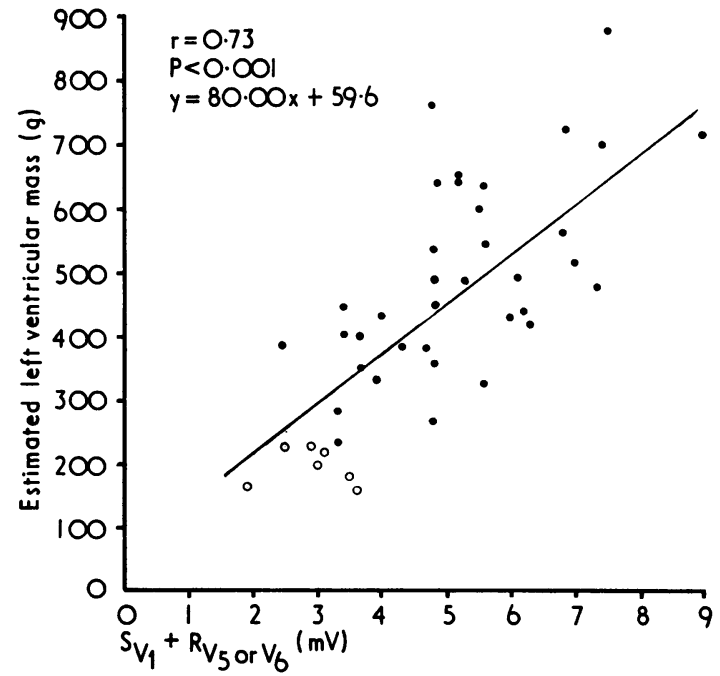

FIG. 4 Relation between left ventricular mass determined echocardiographically and the sum of the $S$ wave in lead $V_{I}$ and the $R$ wave in $V_{5}$ or V6 of the electrocardiogram. Open circles $=$ normal subjects; dots $=$ patients .

The respective $r$ values, 0.90 and 0.73 , proved to be significantly different at the 5 per cent level.

\section{Discussion}

Several authors have shown good correlation between echocardiographic and angiocardiographic measurements of left ventricular wall thickness (Sjögren, Hytönen, and Frick, 1970; Troy et al., 1972; Murray et al., 1972). The cube of the ultrasound left ventricular internal dimension has been shown to correlate closely with left ventricular cavity volume measured by biplane angiocardiography (Feigenbaum et al., 1969; Feigenbaum, 1972; Pombo, Troy, and Russell, 1971; Murray et al., 1972; Gibson, 1973).

In our study, the volume occupied by the left ventricular wall was estimated, using echocardiographic measurements of left ventricular wall thickness (LV) and internal dimension (LVID), by 


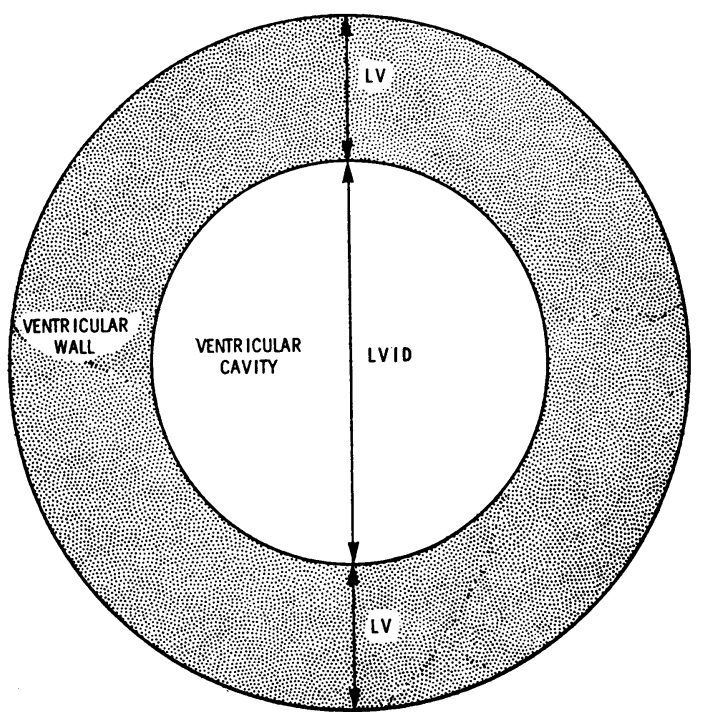

FIG. 5 Diagrammatic cross-section of left ventricle, to show the components of the minor axis of the greater spheroid (left ventricular cavity plus wall).

determining the volume occupied by left ventricular wall plus cavity, i.e. $(2 L V+L V I D)^{3}$, and subtracting from this the estimated left ventricular cavity volume LVID $^{3}$ (Fig. 5). This method of calculation appears preferable to that used by Murray et al. (1972), in their comparison of ultrasound and angiocardiographic left ventricular mass. They used the formula:

Left ventricular wall volume $=(L V+L V I D)^{3}-$ LVID $^{3}$.

However (LVID + LV) does not represent the complete ultrasound dimension of ventricular wall plus cavity. Recalculation of their data using the formula:

Left ventricular wall volume $=(2 L V+L V I D)^{3}-$

LVID $^{3}$

gave substantially greater values for ultrasound left ventricular mass which in absolute terms correlated more closely with the angiocardiographic results and gave an $r$ value of 0.86 compared with the figure of 0.83 which they obtained.

Troy et al. (1972) employed the formula:

Left ventricular wall volume $=\frac{4}{3} \pi\left(\frac{\mathrm{LVID}}{2}+\mathrm{LV}\right)^{2}$. $(\mathrm{LVID}+\mathrm{LV})-\frac{4}{3} \pi\left(\frac{\mathrm{LVID}}{2}\right)^{2} \cdot$ LVID.

This is derived from the basic formula for an ellipsoid of rotation (prolate spheroid) and requires two assumptions. The first is that LVID is a minor axis
(Fortuin et al., I97I; Pombo et al., I97I; Murray et al., 1972; Gibson, 1973), $\frac{\text { LVID }}{2}$ being the appropriate hemiaxis (radius) quantity. The second is that the major axis of the reference figure is twice the length of the minor axes (Sandler and Dodge, 1968; Pombo et al., 197I; Ross et al., 197I). In their formula, therefore, LVID is used as the value of the major hemiaxis of the inner spheroid and this is appropriate. The major axis of the outer spheroid (ventricular wall plus cavity) is, however, represented by LVID + LV; since the minor hemiaxes of this reference figure are each $\frac{\text { LVID }}{2}+L V$, the proper term for its major hemiaxis is $2\left(\frac{L V I D}{2}+L V\right)$, i.e. LVID $+2 L V$.

Recalculation of their data using the corrected formula: Left ventricular muscle volume $=$ $\frac{4}{3} \pi\left(\frac{\mathrm{LVID}}{2}+\mathrm{LV}\right)^{2} \cdot \quad(\mathrm{LVID}+2 \mathrm{LV})-\frac{4}{3} \pi\left(\frac{\mathrm{LVID}}{2}\right)^{2}$ LVID yields closer correspondence between the actual values for ultrasound and angiocardiographic mass and $r$ value of 0.893 compared with their figure of 0.883 . Use of the simplified formula we employed is, of course, equivalent to proper use of the same basic formula, $\pi$ being substituted by 3 . The error involved in this approximation is less than 5 per cent and considered insignificant in the light of the obvious limitations of the basic assumptions necessarily involved.

Various vectorcardiographic measurements have been used in the assessment of left ventricular enlargement. Some, such as the horizontal maximum vector (Rainey et al., 1967), or the sum of the horizontal and frontal maximum vectors (Fowler, Shams, and Keith, 197I), are relatively simple and easy to make. Others, however, such as the left maximum spatial voltage measurement (Hugenholtz and Gamboa, 1964) are too complex for general use. Left ventricular enlargement causes an increase in, and a posterior, leftward, and usually superior shift of, the maximum QRS vector. Vectorcardiographic loops in two planes are required to record these changes fully since they occur in more than one axis. For this study, therefore, the sums of the maximum $Q R S$ vectors in the horizontal and sagittal, and horizontal and frontal, planes were chosen as simple vectorcardiographic indices, together with the maximum horizontal plane vector. All these indices yielded good correlation with ultrasound left ventricular mass. Similarly good correlation has been demonstrated in a study of 22 patients with aortic incompetence (Rainey et al., I967), between 
left ventricular mass measured by angiocardiography and the maximum vector in the horizontal plane, and, in 107 miscellaneous patients (Vine et al., 197I), between time strength integrals of instantaneous spatial vectors and angiocardiographic left ventricular mass.

The scalar electrocardiographic criterion of Sokalow and Lyon (1949), i.e. $S_{\mathrm{V} 1}+R_{\mathrm{V} 5}$ or v6, was chosen as an index of praecordial voltage because it had shown the closest correlation of various praecordial voltage criteria with angiocardiographically determined left ventricular mass (Vine et al., 197I). In this study there was less good correlation between these voltage measurements and ultrasound left ventricular mass than was observed with the vectorcardiographic measurement $(P<0.05)$.

In conditions affecting only the left side of the heart the above recommended vectorcardiographic measurements are a useful noninvasive method of assessing left ventricular mass and are easier to make than the ultrasound measurements, which in some cases may be impossible to obtain. Where there is coexistent right ventricular enlargement, voltage changes arising from the left ventricle may be influenced by those from the right ventricle and the ultrasound method appears more suitable, provided that uniformity of left ventricular wall thickness can reasonably be assumed.

Our thanks are due to the following: Dr. H. A. Fleming and Mr. B. B. Milstein for advice and permission to study their patients; Miss Vivien Key for technical assistance; Messrs. R. Hankar (University of Cambridge) and J. Seldrup (Geigy Pharmaceuticals Ltd) for statistical help; Department of Medical Photography, Addenbrooke's Hospital, for reproduction of the figures.

\section{References}

Abbott-Smith, C. W., and Chou, T. C. (1970). Vectorcardiographic criteria for the diagnosis of left ventricular hypertrophy. American Heart fournal, 79, 36r.

Bardeen, C. R. (1918). Determination of the size of the heart by means of the $x$-rays. American fournal of Anatomy, 23, 423.

Bristow, J. D., Porter, G. A., and Griswold, H. E. (1961). Observations with the Frank system of vectorcardiography in left ventricular hypertrophy. American Heart fournal, 62, 621 .
Feigenbaum, H. (1972). Clinical applications of echocardiography. Progress in Cardiovascular Diseases, 14, 531.

Feigenbaum, H., Wolfe, S. B., Popp, R. L., Haine, C. L., and Dodge, H. T. (1969). Correlation of ultrasound with angiocardiography in measuring left ventricular diastolic volume. American fournal of Cardiology, 23, 111 .

Fortuin, N. J., Hood, W. P., Sherman, M. E., and Craige, E. (197I). Determination of left ventricular volumes by ultrasound. Circulation, 44, 575.

Fowler, R. S., Shams, A., and Keith, J. D. (197I). Vectorcardiography, p. 568. North-Holland Publishing Company, Amsterdam.

Frank, E. (1956). An accurate, clinically practical system for spatial vectorcardiography. Circulation, 13, 737.

Gibson, D. G. (1973). Estimation of left ventricular size by echocardiography. British Heart fournal, 35, 128.

Hugenholtz, P. G., and Gamboa, R. (1964). Effects of chronically increased ventricular pressure on electrical forces of the heart. Circulation, 30, 511 .

Mazzoleni, A., Wolff, R., and Wolff. L. (1959). The vetorcardiogram in left ventricular hypertrophy. American Heart Fournal, 58, 648.

Murray, J. A., Johnston, W., and Reid, J. M. (1972). Echocardiographic determination of left ventricular dimensions, volumes and performance. American fournal of Cardiology, 30, 252.

Pombo, J. F., Troy, B. L., and Russell, R. O. (1971). Left ventricular volumes and ejection fraction by echocardiography. Circulation, 43, 480.

Rainey, R. L., Besseghini, I., Witham, A. C., and Edmonds, J. H. (1967). Vectorcardiographic correlations with mass, volume, and other hemodynamics in aortic insufficiency. Circulation, 36, Suppl. II, 215.

Ross, J., Sonnenblick, E. H., Taylor, R. R., Spotnitz, H. M., and Covell, J. W. (197I). Diastolic geometry and sarcomere lengths in the chronically dilated canine left ventricle. Circulation Research, 28, 49.

Sandler, H., and Dodge, H. T. (I968). Use of single plane angiocardiograms for the calculation of left ventricular volume in man. American Heart fournal, 75, 325.

Sjögren, A. L., Hytönen, I., and Frick, M. H. (I970). Ultrasound measurements of left ventricular wall thickness. Chest, 57, 37.

Sokalow, M., and Lyon, T. P. (1949). The ventricular complex in left ventricular hypertrophy as obtained by unipolar precordial and limb leads. American Heart fournal, 37, 16r.

Troy, B. L., Pombo, J., and Rackley, C. E. (1972). Measurement of left ventricular wall thickness and mass by echocardiography. Circulation, 45, 602.

Vine, D. L., Finchum, R. N., Dodge, H. T., Bancroft, W. H., and Hurst, D. C. (I971). Comparison of the vectorcardiogram with the electrocardiogram in the prediction of left ventricular size. Circulation, 43, 547.

Requests for reprints to Dr. D. Bennett, Regional Cardiac Unit, Papworth Hospital, Papworth Everard, Cambridge $\mathrm{CB}_{3}$ 8RE. 